\title{
Educating Higher Education Students for Innovative Economies: What International Data Tell Us.
}

\author{
Francesco Avvisati, Gwenaël Jacotin, and Stéphan Vincent-Lancrin ${ }^{1}$
}

\begin{abstract}
As innovation increasingly fuels economic growth, higher education institutions and systems face the challenge of equipping students with the skills required by innovative economies. Using two international surveys of tertiary education graduates five years after their graduation, we show that the innovative, tertiary-educated workforce comprises a mix of graduates holding degrees from all disciplines. The contribution to innovation of different graduates varies by type of innovation. When they assess the strong and weak points of their university education, graduates give a mixed picture of the quality of the education they have received. We then link the propensity to participate in innovation to the relative emphasis on theory and practice in university programmes and conclude by highlighting the importance of a competence-based approach to curriculum and pedagogy.
\end{abstract}

Keywords: higher education; innovation; pedagogy; skills; international comparison; qualifications; system evaluation; curriculum.

\section{Introduction}

What is the broad mix of skills needed in innovative societies and sectors, and how can higher education institutions and innovation policies contribute to fostering this mix? To answer this question, we analyse two international surveys of tertiary graduates five years after their graduation, covering 20 countries, namely the twin surveys Reflex and Hegesco. We show that the innovative workforce by sector of the economy and by type of innovation comprises a broad mix of tertiary education graduates, and present the likelihood of contributing to innovation for graduates in different fields. We then identify the critical individual skills used by the most innovative workforce,

${ }^{1}$ Authors' names are listed in alphabetical order. Corresponding author: Stephan. Vincent-Lancrin@oecd.org. The analyses given and the opinions expressed in this article are those of the authors' and do not necessarily reflect the views of the OECD and of its members. The study was developed as part of the "Innovation Strategy for Education and Training" of the OECD Centre for Educational Research and Innovation (CERI) and benefited from useful comments from Kiira Kärkkäinen and Dirk Van Damme (OECD) as well as from members of the CERI Governing Board. 
and analyse to what extent they are associated with different kinds of pedagogies. We conclude with a call for a broader focus of innovation policies, when those are limited to science and engineering, and suggest that fostering skills for innovation could be an objective of any higher education programme.

We define "skills" as the bundle of knowledge, attributes and capacities that enables an individual to successfully and consistently perform an activity or task, whether broadly or narrowly conceived, and can be built upon and extended through learning. We distinguish three overlapping categories of "skills for innovation": technical skills (know-what and knowhow); skills in thinking and creativity (critical thinking, imagination, creativity); and behavioural and social skills (persistence, conscientiousness, self-esteem, communication, collaboration). They correspond to building blocks of the individual capacity to contribute to innovation.

In this article, we present findings on skills and education for innovation based on the analysis of two surveys of tertiary graduates five years after their graduation, namely the twin surveys Reflex and Hegesco. The Reflex survey on professional workers in knowledge-based societies was conducted in 2005 in 14 European countries and Japan, on the basis of representative samples of tertiary graduates (ISCED 5a). The Hegesco survey was carried out in 2008 to extend the coverage of Reflex to 5 additional European countries. The analysis of the twin surveys covers the following countries: Austria, Belgium, Czech Republic, Estonia, Finland, France, Germany, Hungary, Italy, Japan, Lithuania, the Netherlands, Norway, Poland, Portugal, Slovenia, Spain, Switzerland, Turkey, and the United Kingdom. The Proflex survey provides similar information for three additional countries in Latin America (Chile, Mexico, Uruguay), but only for a sub-set of questions. ${ }^{2}$

Respondents were asked about the importance of 19 skills in their job, their self-assessed level in these skills, their involvement in different types of innovation, as well as questions about some characteristics of their tertiary education programme and how they assess it retrospectively. The surveys thus allow one to study the associations between the subject studied, the prevalence of different teaching activities during tertiary education, innovation and skills (self-reported). Allen and van der Velden ${ }^{3}$ present the

2 The PROFLEX project, which is coordinated by the Centro de Gestión de la Calidad y del Cambio at the Universidad Politécnica de Valencia, has been kind enough to share the files of these three countries with us : its questionnaire is more or less similar to those of REFLEX and HEGESCO but did not include the innovation questions that we have used to identify the innovative workforce.

3 Jim Allen, and Rolf van der Velden, eds., The Flexible Professional in the Knowledge Society. New Challengesfor Higher Education (Dordrecht: Springer, 2011). 
database as well as numerous other analyses that were derived from it, including one on innovation. ${ }^{4}$

The analysis allows us to cast light on several questions relevant to education and innovation policy makers.

\section{A broad mix of qualifications for innovation}

A first question is about the nature of qualifications needed for innovation. One conclusion of the OECD Innovation Strategy is that innovation requires a broad mix of qualifications. ${ }^{5}$ This conclusion has important policy implications, as innovation policies concerned with human resources tend to have a narrow focus on scientists and engineers (and sometimes entrepreneurship).

One first piece of evidence of this required mix lies in the professional qualifications sought by innovative businesses, as presented by Toner ${ }^{6}$ for example. In 2006, the Australian innovation survey (ABS) asked businesses that innovated over the previous two years about the qualifications of the people they recruited to develop new goods or services or implement new operational or organisational/managerial processes. About half $(47.4 \%)$ of innovating businesses recruited in 2004 or 2005. For their new vacancies, just $2.2 \%$ of the firms sought scientific qualifications, and $9.3 \%$, engineering qualifications. Most frequently, these vacancies required general business skills $(22.6 \%)$, marketing skills (18.2\% of firms), or product management skills ( $10.1 \%$ of firms). The mix of qualifications sought by these innovative businesses shows differing patterns across sectors: science and engineering skills are mostly sought by innovative firms in manufacturing and resourcerelated industries (Mining, Electricity-Gas-Water), while innovative firms in service sectors predominantly seek marketing, general business and information technology (IT) skills.

Our analysis of Reflex and Hegesco casts additional light on this mix of skills by identifying the mix of fields studied in tertiary education by the most innovative professionals. Reflex and Hegesco include questions on the

${ }^{4}$ Jean-Jacques Paul, "Graduates in the Knowledge and Innovation Society," in The Flexible Professional in the Knowledge Society. New Challenges for Higher Education, ed. Jim Allen and Rolf van der Velden (Dordrecht: Springer, 2011), 111-37.

${ }^{5}$ Organisation for Economic Co-operation and Development (OECD), The OECD Innovation Strategy: A Head Start on Tomorrow (Paris: OECD Publishing, 2010).

${ }^{6}$ Phillip Toner, "Workforce Skills and Innovation: An Overview of Major Themes in the Literature," OECD Education Working Paper no. 55, Paris: OECD Publishing, 2011, http:// www.oecd-ilibrary.org/education/workforce-skills-and-innovation_5kgk6hpnhxzq-en. 
involvement of professionals in innovation. Respondents are asked to report whether they work in an organisation that innovates, and whether they have a role in introducing these innovations in their organisation. We combine those questions and define "highly innovative" professionals as those working in innovative organisations and involved in the introduction of innovations: they represents on average $55.6 \%$ of tertiary-educated professionals in the surveyed countries.

The highly innovative workforce across different sectors comprises a varied mix of academic qualifications (Figure 1). In manufacturing industries, over 50\% of tertiary-educated employees involved in innovation have an engineering

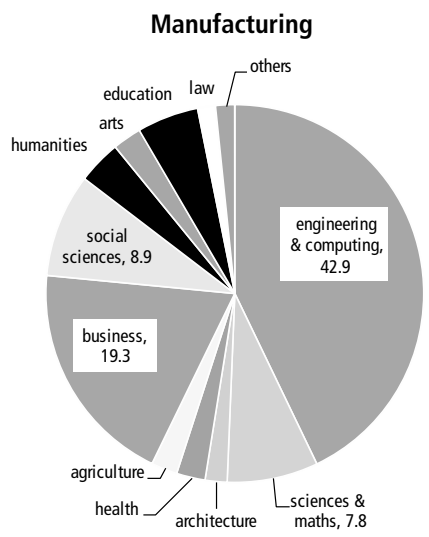

Business activities

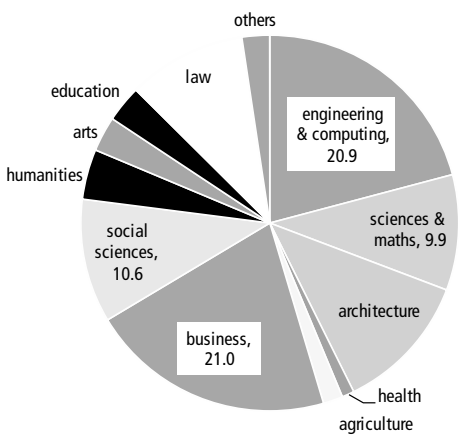

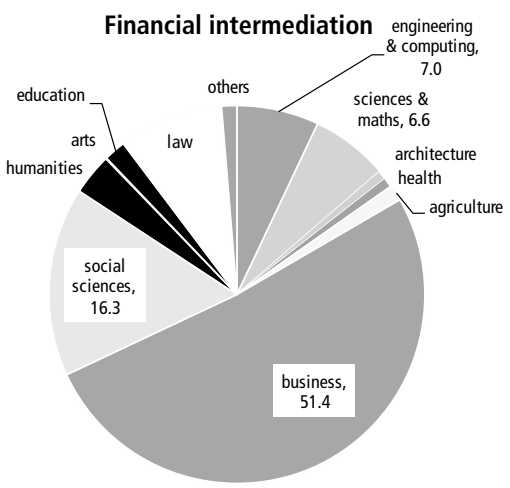

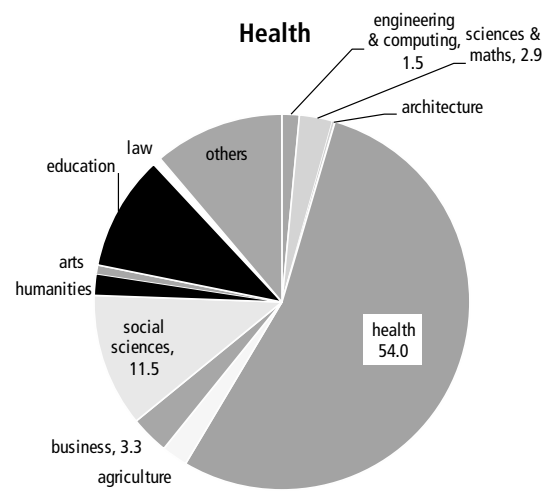

Figure 1

Field of education of the innovative workforce, by sector of activity.

Source: Authors' calculation. Based on Reflex and Hegesco. 
(42.9\%) and science (7.8\%) degree. This proportion shrinks in business activities (including computer-related activities, research and development, consultancy and advertisement), where engineering graduates represent $20.9 \%$ of tertiaryeducated employees involved in innovation and science graduates $9.9 \%$; it is even smaller in finance, where the proportions are $7.0 \%$ and $6.6 \%$ respectively. In these service industries, the bulk of the highly innovative workforce is formed by business graduates, social sciences graduates, and law graduates.

The composition of the highly innovative workforce varies by type of innovation too (Figure 2). For example, engineering and computing graduates represent over one fourth $(25.3 \%)$ of all graduates contributing to technology innovation (but only $13.5 \%$ of the total graduate workforce); they are also over-

Product innovation

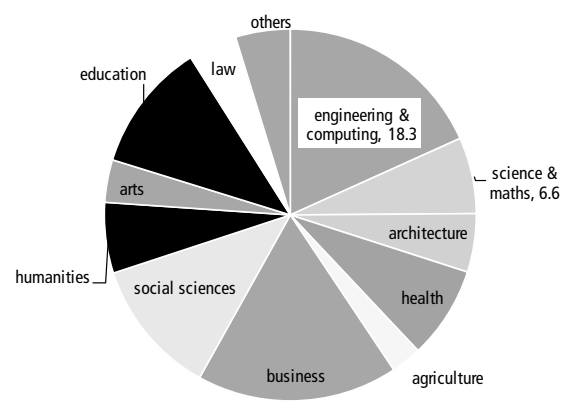

Knowledge innovation

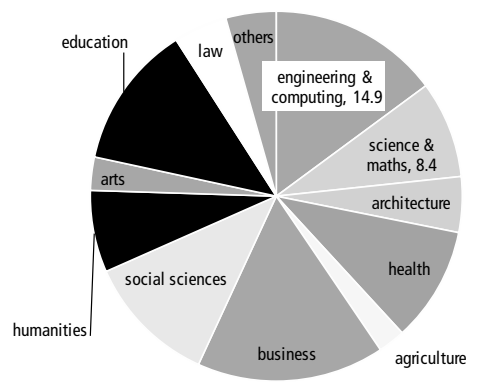

Technology innovation

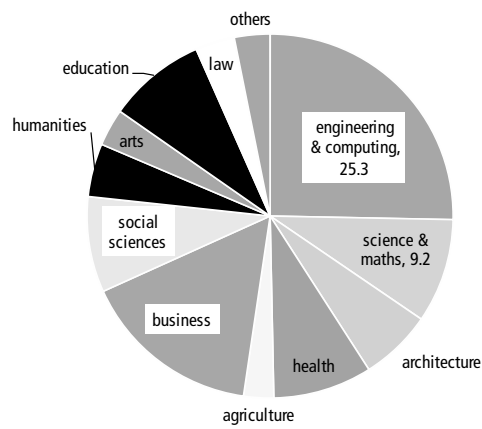

Any innovation

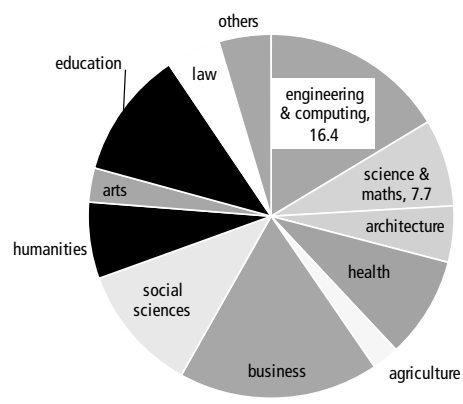

Figure 2

Field of study of the innovative workforce, by type of innovation.

Source: Authors' calculation. Based on Reflex and Hegesco. 
represented among graduates contributing to product innovation (18.3\%), but only slightly over-represented among knowledge or methods innovators (14.9\%). Science or mathematics graduates, who represent $6.7 \%$ of the graduate workforce, are over-represented among technology innovators $(9.2 \%)$ and among knowledge innovators (8.4\%), but not among product innovators $(6.6 \%)$.

Another way to assess the contribution of tertiary graduates from different fields to innovation lies in the likelihood that they have a highly innovative job five years after graduation. Here again, the analysis of Reflex and Hegesco shows that a significant proportion of professionals with tertiary degrees from all fields work in highly innovative jobs (Figure 3). Over $45 \%$ of tertiary graduates
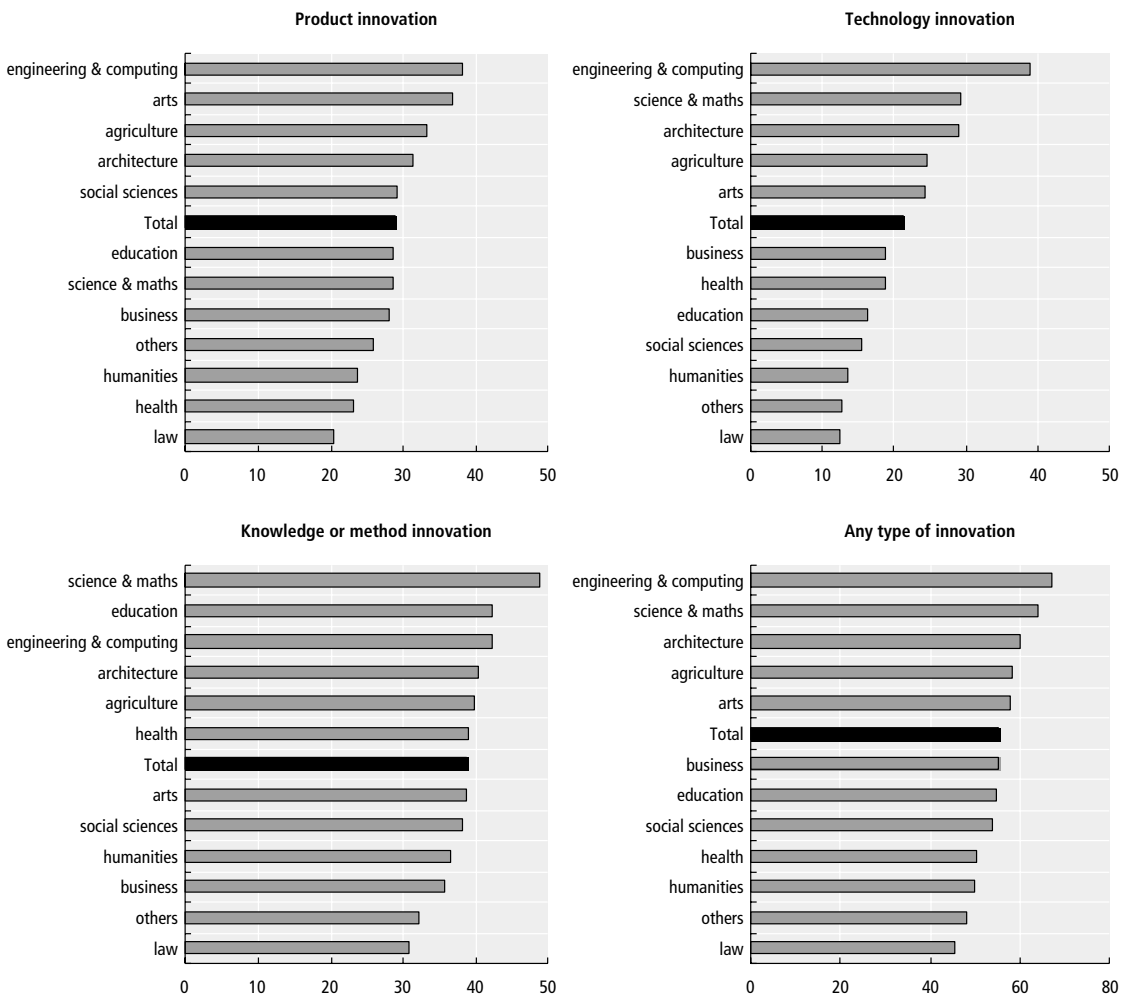

Figure 3

Percentage of tertiary graduates from specific fields having a highly innovative job.

Source: Authors' calculation. Based on Reflex and Hegesco. 
from any field participate in at least one type of innovation. Science and engineering graduates are more likely to participate in some form of innovation (over $60 \%$ of them do), but a significant percentage of graduates from other fields also have a highly innovative job $-55 \%$ for a tertiary education graduate on average, and about $58 \%$ for arts and agriculture graduates. This contribution varies across types of innovation: graduates in arts and in engineering have the same likelihood of participating in product innovation. In knowledge or method innovation, the differences across fields are relatively small, whereas they are much greater for technology innovation, in which engineers are significantly more likely than others to have a highly innovative job.

As far as fields of study are concerned, the analysis of Reflex and Hegesco confirms that a broad mix of specialisations and qualifications is needed for innovation. The traditional view that innovators come mainly from science and engineering graduates is partly confirmed by our analysis: whatever the innovation type, they are among the most likely to have a highly innovative job. However, it also shows that an overly exclusive focus on the training of scientists and engineers to promote innovation is largely misplaced, given that other graduates do also contribute significantly to innovation and that the relative importance of the manufacturing sector decreases in most OECD economies.

\section{Critical skills for highly innovative jobs}

Professional and academic qualifications allow us to understand the extent to which certain bundles of disciplinary skills are used in the innovation process. While it is interesting to see the relevance of higher education programmes to innovation, it does not allow us to identify the specific skills that matter the most in highly innovative jobs. Reflex and Hegesco allow us to go one step further and to identify some specific skills that matter for innovation at the individual level. By comparing (self-reported) job requirements of highly innovative and non-innovative jobs, the most critical skills for innovation which distinguish innovators from non-innovators can be identified. We define "non-innovative jobs" as those held by professionals reporting that their organisation does not innovate and that they do not contribute to the introduction of innovation.

Respondents to Reflex and Hegesco were asked to indicate the level of 19 skills that their current job requires. Highly innovative professionals have higher job requirements for any single skill than non-innovative professionals. Highly innovative jobs are thus more demanding. The critical skills that distinguish innovators from non-innovators the most are creativity ("come up with new ideas and solutions" and the "willingness to question ideas"), 
followed by the "ability to present ideas in audience", "alertness to opportunities", "analytical thinking", "ability to coordinate activities", and the "ability to acquire new knowledge" (Figure 4). These critical skills match our assumptions on individual skills for innovation.

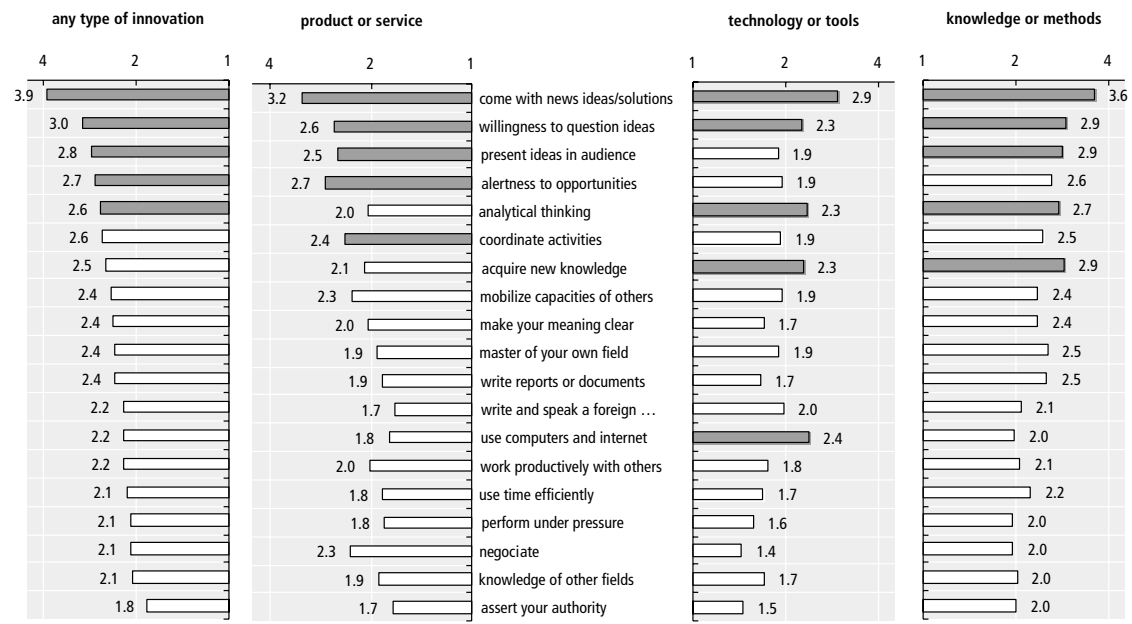

Figure 4

Critical skills for the most innovative jobs, by type of innovation

Tertiary-educated workers who contribute to their organisation's innovation activities face higher skill requirements than non-innovative graduates.

Source: Authors' calculation. Based on Reflex and Hegesco. Odds ratios correspond to the likelihood of mentioning the skill as required for workers in innovative jobs, compared to workers in non-innovative jobs. Generalised odds ratio are computed from logistic regressions controlling for country and sector of activity. The five most critical skills are highlighted for each type of innovation.

The different types of innovation, though, require slightly different skill profiles. Professionals who are contributing to product innovation report high requirements for their job especially in terms of creativity ("come up with new ideas and solutions", "alertness to opportunities", "willingness to question ideas"). For technology innovation, behind "coming up with new ideas and solutions", the most critical skills seem to be the "ability to use computers and the internet", "analytical thinking", and the "ability to rapidly acquire new knowledge". Graduates contributing to innovation of knowledge or methods, in contrast, need to complement creativity ("come up with new ideas and solutions", "willingness to question ideas") and thinking skills ("analytical thinking", "ability to rapidly acquire new knowledge") with 
persuasion and communication skills ("the ability to present ideas to an audience") (Figure 4).

\section{Fostering skills for innovation in higher education}

Our analysis of Reflex and Hegesco does not only allow us to identify which skills contribute to innovation, but also to start understanding better how higher education institutions can foster them. The data presented in Figure 3 show that higher education institutions and programmes do produce a large share of graduates who will contribute to innovation. Reflex, Hegesco (and in some cases Proflex) allow us to assess higher education systems in terms of skills development, but also to associate some pedagogies to subsequent innovation or to the development of certain skills.

First, respondents to the Reflex, Hegesco, and Proflex surveys were asked to give a retrospective assessment of the three top strengths and weaknesses of their higher education programmes in terms of skills development. Professionals from Europe, Japan and Latin America tend to agree that universities developed mostly their thinking and learning skills (analytical thinking and the ability to rapidly acquire new knowledge) as well as their domain-specific expertise (mastery of their own field or discipline). At the same time, students are dissatisfied with the level of social and behavioural skills acquired through their university programme: former students in Japanese and European universities are much more likely to lament shortcomings of their university programmes regarding the development of social and behavioural skills (collaboration, communication, and leadership skills) than concerning critical thinking and subject-based skills (Figure 5). Some of the critical skills for innovation only receive average assessments: "presenting ideas" comes fourth among weaknesses, and "coming up with new ideas and solutions" is not considered to be a particularly strong point of university education. There may thus be room for improvement in the fostering of these skills.

These findings can be supplemented by two recent studies using direct standardised test measures of generic skills to assess whether higher education fosters critical thinking. Two large-scale assessments of undergraduate students in the United States $^{7}$ and Colombia ${ }^{8}$ demonstrate that genuine gains

${ }^{7}$ Richard Arum, and Josipa Roksa, Academically Adrift: Limited Learning on College Campuses (Chicago: University of Chicago Press, 2011).

8 Anna Rosefsky Saavedra and Juan Esteban Saavedra, "Do Colleges Cultivate Critical Thinking, Problem Solving, Writing and Interpersonal Skills?" Economics of Education Review 30, no. 6 (2011): 1516-26. 

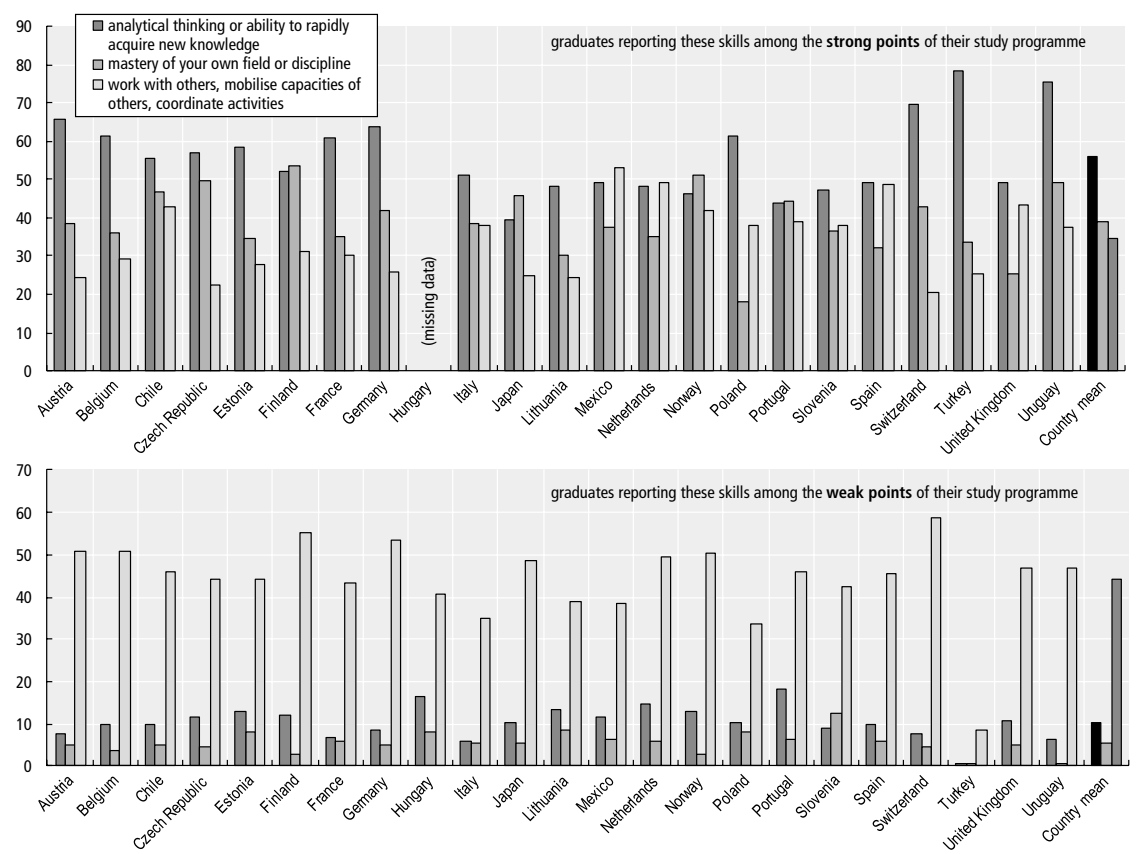

Figure 5

How professionals assess the strong and weak points of skills development in university.

Source: Authors' calculation. Based on Reflex, Hegesco and Proflex.

in non-domain specific skills can be attributed to the learning environment of the particular institution attended. The results highlight in particular the contribution of high quality higher education institutions to students' critical thinking skills. At the same time, many students do not show significant progress, and have been described as "academically adrift"; importantly, however, student progress (or absence thereof) is consistently and significantly associated with the quality of teaching and learning inputs. The OECD feasibility study on the Assessment of Higher Education Learning Outcomes (AHELO) may help to cast light on these questions in the future. ${ }^{9}$

A second question that we investigated is whether some higher education pedagogies are more effective than others in preparing students for highly

${ }^{9}$ Organisation for Economic Co-operation and Development (OECD), Assessment of Higher Education Learning Outcomes (AHELO): Feasibility Study Report. Volume 2 - Data Analysis and National Experiences (Paris: OECD Publishing, 2013). 
innovative jobs. Reflex and Hegesco databases can be used to characterise the pedagogy of tertiary education programmes. Using factor analysis techniques (multiple correspondence analysis), we identify two main orientations ("theory" and "practice") that distinguish programmes' profiles: each programme can then be given a "theory score" and a "practice score" based on the students' report. The theory score is mainly determined by an emphasis in the study programme given to lectures, teacher as the main source of information, as well as theories and paradigms. The practice score is mainly determined by an emphasis on group assignments, participation in research projects, internships, work placement, facts and practical knowledge, project and/or problem-based learning, and oral presentations by students.

Across most disciplines and countries, graduates are more likely to participate in innovation processes after having attended tertiary education programmes stressing practical knowledge, such as student-led projects and problem-based learning (Figure 6). Theory-based forms of instruction, such as lectures and the learning of theories and paradigms, have a positive, but weaker association with innovation.

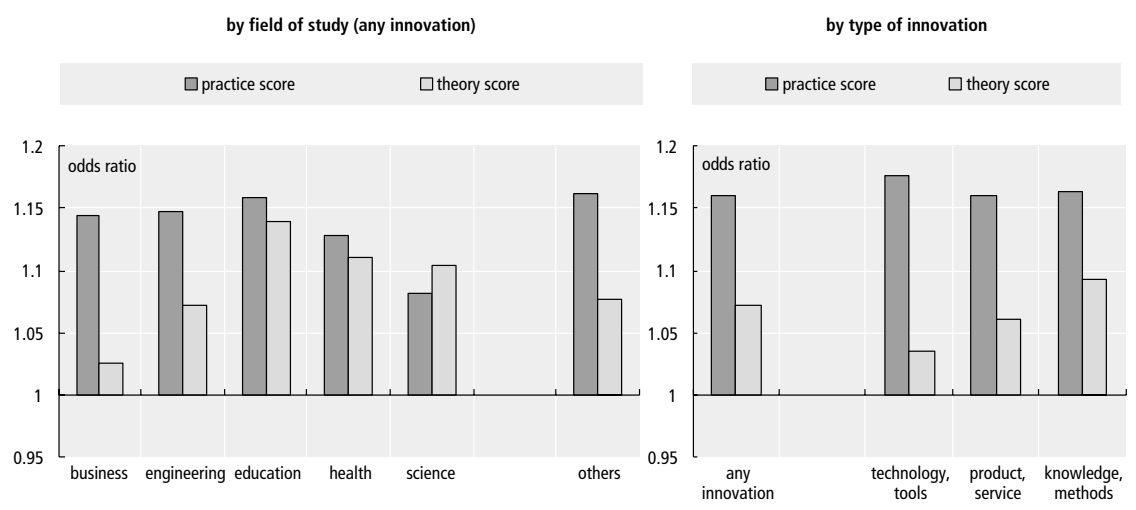

Figure 6

How innovators describe their study programme relative to non-innovators Relative emphasis on theory- and practice-based forms of instruction.

Source: Authors' calculation. Based on Reflex and Hegesco.

In fact, the way in which graduates describe their university programme is a good predictor of how they contribute to innovation. Innovators and noninnovators indeed emphasise to a different degree practice-based forms of 
instruction and theory-based forms of instruction in their description of study programmes.

The association between the pedagogical model of the university programme and the proportion of alumni contributing to innovation in their early career varies, however, depending on the field of study. At one extreme are engineering and business graduates, for whom the amount of practice-based instruction is strongly associated with subsequent innovation. In science, education and health fields, on the other hand, greater emphasis on theory-based instruction has a positive and equally strong association with innovation as practice-based instruction. This difference may result from the different ways one can contribute to innovation. Science graduates who contribute to innovation in knowledge or methods describe their programmes as particularly theory-intensive. Engineering and business graduates' ability to contribute to innovation seems to depend critically on their exposure to hands-on instruction. In general, practice-based pedagogies have a stronger association with innovation. Theory-based pedagogies are increasingly associated with innovation as one moves from technology innovation to knowledge innovation through product innovation (Figure 6).

Teaching and learning forms in higher education also have distinctive patterns of association with the level of skills self-reported by tertiary educated professionals (Figure 7). Differences in the emphasis on theoretical knowledge and conceptual understanding are particularly associated with reported ability in analytical thinking, in acquiring new knowledge, and in writing. On the other hand, differences in the emphasis of programmes on practical knowledge, on student-led projects and on problem-based learning are reflected in the level of creative skills, of oral communication skills and of teamwork and leadership skills of students ("ability to come up with new ideas and solutions", "alertness to new opportunities"; "ability to present products", "ideas or reports to an audience"; "ability to negotiate effectively", "to assert own authority", "to work productively with others and to mobilise their capacities").

Causal interpretations of these associations are not granted: students may well enrol in programmes which emphasise conceptual understanding to a high degree because they possess high analytical skills to start with, or may prefer programmes stressing practice-based methods because they are good team-workers. In other words, because students who attend different programmes have different skills strengths and interests before their enrolment, we cannot be sure that they were developed (rather than just reinforced) by their higher education programmes - or type of instruction. 


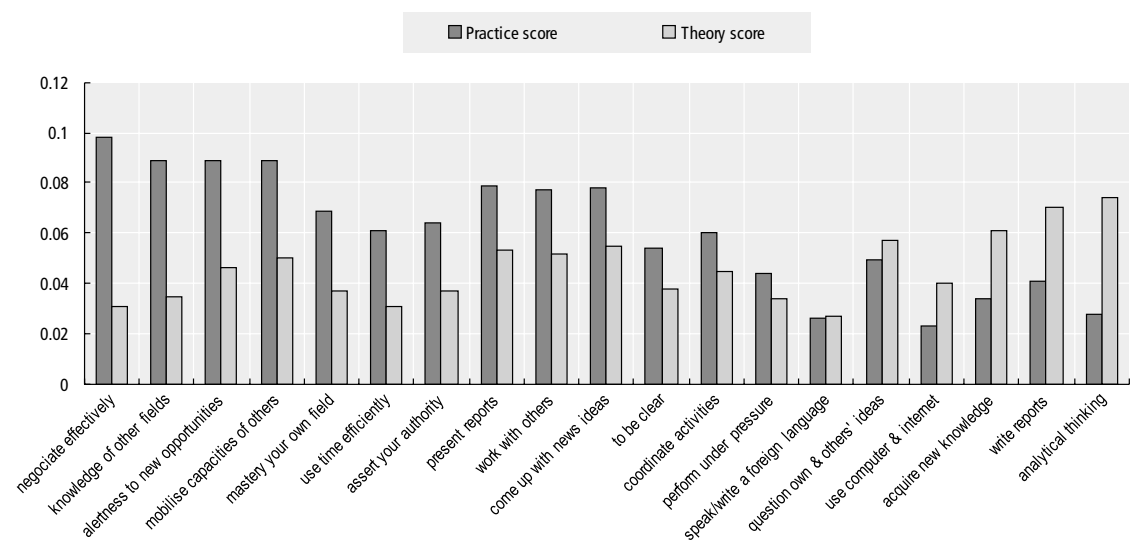

Figure 7

The effect of theory and practice emphases in university teaching on different skills (self-reported levels).

Note: Skills are ranked according to the difference between the effect size on practicebased teaching forms and the effect size on theory-based teaching forms.

Source: Authors' calculation. Based on Reflex and Hegesco.

Nevertheless, tertiary educated professionals themselves tend to attribute at least some of their current skills to the merits of particular programmes in which they enrolled (Table 1). The higher the emphasis on theory in their studies, the more likely students are to report analytical thinking skills, the ability to rapidly acquire new knowledge, and expertise in their own field as strong points of their study programme. On the other hand, the higher the emphasis on practice, the more likely it is that creativity, oral communication, teamwork and leadership skills are cited as strong points of the study programme.

In general, the associations between pedagogy in their tertiary studies and skill levels self-reported by professionals (Figure 7) are in line with the associations between pedagogy and the assessment of the strengths of their university programmes (Table 1 ).

The patterns of association suggest that theory-intensive programmes are particularly effective for developing thinking skills, and that practiceintensive programmes are more effective for developing creativity, teamwork, and leadership skills. A diverse offer of pedagogies is the most effective way to foster all skills for innovation in the working population. 


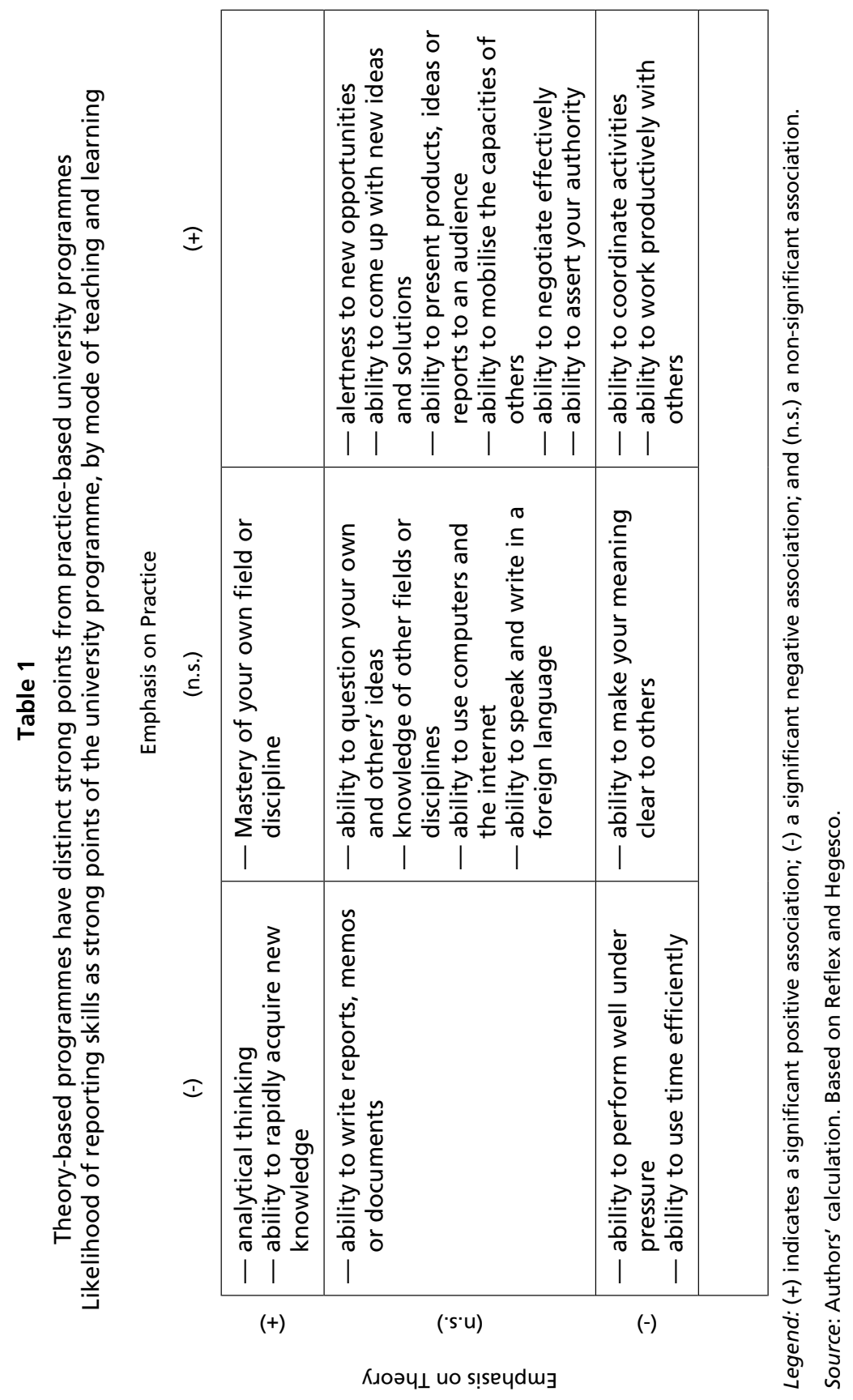




\section{Concluding remarks}

To conclude, we point to two implications of our analysis for innovation policy makers and the tertiary education community. We first argue that innovation policies focusing on scientists and engineers should generally have a broader disciplinary focus. We then suggest that tertiary education institutions should try to foster skills that are important for innovation regardless of the discipline, and that the TUNING community should build skills for innovation as an integral part of its agenda on competence-based approaches to curriculum.

Conventional innovation policies concerned with human resources tend to try to increase the number of Science, Technology, Engineering and Mathematics (STEM) graduates, which is seen as critical for countries' innovation capacity. Our analysis suggests that innovation requires people with diverse qualifications and that innovation policies with a broader focus than STEM could be warranted, even though STEM graduates arguably play an important role in innovation. They represent an overwhelming proportion of patent holders and are highly represented among workers involved in all types of innovation, but graduates from other disciplines tend to be more involved in the innovation process than generally acknowledged.

Science and (especially) engineering graduates are highly represented among patent holders. In the United States, the National Survey of College Graduates shows that $73.8 \%$ of patent holders have a science or engineering degree. More precisely, some majors (electrical engineering, chemical engineering, mechanical/industrial engineering, and physics) are associated with a very high patenting activity (over $6 \%$ of graduates from these fields hold some patent), but the patenting activity is much lower for the remaining STEM majors. ${ }^{10}$

While patents are often used as a proxy for innovation intensity, they only concern a small share of innovation, as not all types of innovation need to be or can be patented. Increasing the number of STEM-trained graduates may therefore lead to a larger number of patents, granted that these graduates select into the appropriate majors, but is certainly not the only way of increasing the innovative activity in the economy. The broader concept of innovation used in Reflex and Hegesco gives a different picture. Around eight percent $(7.8 \%)$ of tertiary-educated professionals in a highly innovative

${ }^{10}$ Jennifer Hunt et al., "Why Don’t Women Patent?" NBER Working Paper No. 17888, Cambridge, MA: National Bureau of Economic Research (NBER), 2012, http://www.nber.org/ papers/w17888. 
job hold a science or mathematics degree, and $16.5 \%$ a degree in engineering or computing. Graduates from STEM-related fields (agriculture, health, architecture) account for an additional sixth of the tertiary-educated highly innovative workforce $(16.4 \%)$. However, half of highly innovative professionals have a background in business $(17.5 \%)$, education $(11.4 \%)$, social sciences $(11.1 \%)$, or other non-STEM fields.

The analysis of the distribution of STEM graduates across sectors and types of innovation suggests that a focus of innovation policies related to human resources on the disciplinary competences of STEM graduates may be relevant in contexts where innovation policies are limited to the manufacturing sector and are mainly concerned with fostering technology innovation. However, given the declining share of value creation taking place in manufacturing in the OECD area, this may not be in line with the current reality of innovation.

Another reason why innovation policies try to stimulate STEM education comes from a concern about possible skills shortages in science and engineering, which could be a possible threat to innovation capacity.

This widespread concern about the falling interest in science and engineering and possible future shortages in scientists and engineers is generally not warranted. In the OECD area, the number of degrees awarded in tertiary education science or engineering programmes has continued to increase in the past decade (2000-2009). This absolute increase has been slower than the increase in the total number of degrees awarded $(2.7 \%$ annual growth between 2000 and 2009 for science and 3.8\% for engineering, compared to $4.4 \%$ increase annually on average), leading to a decreasing relative share of STEM graduates in successive cohorts of tertiary education graduates. There are a few exceptions though: the number of science and mathematics degree awarded each year has decreased over the last decade in Chile, Estonia, France, Greece, Ireland, Italy and Spain; and the number of engineering degrees has decreased in Chile, Estonia, and Ireland. Despite these exceptions, there is overall no strong evidence of a shortage (or coming shortage) of tertiary education graduates in STEM disciplines in the OECD area.

A second interesting result of our analysis is that the mastery of one's own field is not among the very top skills that differentiate the most highly innovative from less innovative professionals (Figure 4). This is not to say that the mastery of a field is not important. Regardless of their involvement in innovation, the mastery of one's field is reported as very important by 54\% of all professionals - which makes it rank 7 . Our point is more that many of the critical skills for innovation can be fostered in all domains, even though it could take a different shape from one subject to the other. 
Today's STEM graduates may not be demanded for their technical skills in these subjects, but for their strengths in other skills. Indeed, science and engineering graduates earn higher salaries even in jobs that do not require their technical skills. ${ }^{11}$ Employers may reward valued behavioural and social skills, or better thinking skills, or just the higher selectivity and prestige that characterise science and engineering in many countries. If today's STEM graduates partially owe their success to skills that are not STEM-specific, a promising way of increasing the innovative capacity of the future workforce would be to strengthen these skills for all pupils and students, irrespective of their field of study.

Several innovative models of instruction are being experienced worldwide, generally building on problem-based learning. A fashionable trend lies in design thinking, that is, the application of some specific innovation methods to solving real life problems which brings together people with different backgrounds. Design thinking has inspired various tertiary education institutions and programmes in the world, be they degree-granting or not. Examples include the d.school at Stanford University (United States), the design factory at Aalto University (Finland), the i-school at Tokyo University (Japan), or the Master's in innovation, design, entrepreneurship and arts (IDEA) at EMLyon business school and Ecole Centrale de Lyon (France), the Srishti School of Art, Design and Technology in Bangalore (India). Numerous other innovative initiatives try to develop all sets of skills for innovation by rethinking their teaching and make sure that students can get deeper and broader learning.

Given these developments and the skills needs of economies driven by innovation, a research agenda for the higher education community is to evaluate whether these programmes actually manage to develop a broader mix of skills for innovation and whether their graduates end up in highly innovative jobs. For the TUNING community more specifically, one question is whether these new questions and approaches require a retuning of TUNING. While the Bologna process has already led to a certain shift towards more skills-based approaches to higher education programmes, ${ }^{12}$ a new challenge is to remould the disciplinary culture of the faculties that remains predominant in higher education into a skillsbased culture.

11 Anthony P. Carnevale, Nicole Smith, and Michelle Melton, "STEM," Georgetown University Center for Education and the Workforce, 2011, http://cew.georgetown.edu/stem.

${ }_{12}$ OECD, Higher Education to 2030, Volume 2, Globalisation (Paris: OECD Publishing, 2009). 


\section{Bibliography}

Allen, Jim, and Rolf van der Velden, eds. The Flexible Professional in the Knowledge Society. New Challenges for Higher Education. Dordrecht: Springer, 2011.

Arum, Richard, and Josipa Roksa. Academically Adrift: Limited Learning on College Campuses. Chicago: University of Chicago Press, 2011.

Carnevale, Anthony P., Nicole Smith, and Michelle Melton. "STEM.” Georgetown University Center for Education and the Workforce, 2011. http://cew. georgetown.edu/stem.

Hunt, Jennifer, Jean-Philippe Garant, Hannah Herman, and David J. Munroe. "Why Don't Women Patent?" NBER Working Paper No. 17888. Cambridge, MA: National Bureau of Economic Research (NBER), 2012. http://www.nber.org/ papers/w17888.

Organisation for Economic Co-operation and Development (OECD). Higher Education to 2030, Volume 2, Globalisation. Edited by Stéphan Vincent-Lancrin and Kiira Kärkkäinen. Paris: OECD Publishing, 2009.

- The OECD Innovation Strategy: A Head Start on Tomorrow. Paris: OECD Publishing, 2010.

- Assessment of Higher Education Learning Outcomes (AHELO): Feasibility Study Report. Volume 2 - Data Analysis and National Experiences. Paris: OECD Publishing, 2013.

Paul, Jean-Jacques. "Graduates in the Knowledge and Innovation Society." In The Flexible Professional in the Knowledge Society. New Challenges for Higher Education, edited by Jim Allen and Rolf van der Velden. 111-37. Dordrecht: Springer, 2011.

Saavedra, Anna Rosefsky, and Juan Esteban Saavedra. "Do Colleges Cultivate Critical Thinking, Problem Solving, Writing and Interpersonal Skills?" Economics of Education Review 30, no. 6 (2011): 1516-26.

Toner, Phillip. "Workforce Skills and Innovation: An Overview of Major Themes in the Literature." OECD Education Working Paper no. 55. Paris: OECD Publishing, 2011. http://www.oecd-ilibrary.org/education/workforce-skills-andinnovation_5kgk6hpnhxzq-en. 